\title{
Research on the Service Quality of Personal Online Banking from the Perspective of the New Generation
}

\author{
Lingzhi Zeng \\ School of Business Administration \\ Guangzhou College of Technology and Business, \\ Guangzhou, China
}

\author{
$\mathrm{Na} \mathrm{Wu}{ }^{*}$ \\ School of Business Administration \\ Zhongnan University of Economics and Law \\ Wuhan, China \\ *Corresponding Author
}

\begin{abstract}
With the development of Internet technology, online banking is developing faster and faster in China. For the traditional bank, the online bank have the advantages of lower operating costs, lower transaction costs, better customer service mode, better customer service content. The online bank broke the limitation of time, region and the way to trade, which Greatly facilitate the majority of customers. This study takes online banking of China as the research object, from the perspective of the new generation of consumers, according to the theory of SERVOQUAL service quality analysis frame, designed the questionnaire of customer satisfaction of China online banking. This paper analyzes the service quality of online banking of bank of China, and after a statistical description, obtains the customer satisfaction level of online banking of bank of China in five aspects, such tangible, guaranteed, empathic, reliable and responsive and safe, and establishes corresponding countermeasures to the existing problems.
\end{abstract}

Keywords-service quality; online banking; SERVOUAL model

\section{INTRODUCTION}

With the rapid innovation and development of science and technology, the development of e-commerce is changing with each passing day. The number of online bank users in China is growing at an amazing speed, especially the new generation of young users, so that online banking has a broad development market, gradually become the new focus and focus of the competition of commercial Banks. In the process of fierce competition of online banking business of commercial Banks, the new generation has paid more and more attention to the service quality of online banking business. However, the evaluation of online banking users on their service quality and service effect is generally not high. On the one hand, this phenomenon is caused by the deterioration of the overall credit environment of the society, the unsound relevant laws and regulations, the unsound network infrastructure and other macro factors; on the other hand, it is restricted by the micro factors such as the imperfect system and measures of service quality management of commercial Banks. According to the statistical data of China Internet network information center, the online bank users in China do not rate the online bank they use in terms of service quality or service satisfaction.
Through the investigation of the new generation of consumers, this paper obtains a comprehensive statistical index to understand consumers' expectations and requirements on online banking. Through data analysis, the paper finds out the service indicators that consumers are mainly concerned about and the indicators that affect the service quality of enterprises, and defines the advantages and disadvantages of online banking and the efforts to meet these expectations and requirements. For enterprises to improve the quality of service, improve management methods to improve the level of management, continue to carry out system innovation and technological innovation, improve the competitiveness of enterprises to provide accurate basis.

\section{TheORETICAL ANALYSIS AND Model CONSTRUCTION}

\section{A. Literature Review}

When conducting empirical research and analysis on commercial Banks in different countries and regions, foreign scholars mainly study the service quality of online Banks based on rational behavior theory, technology diffusion theory and technology acceptance model. Sohail and Shan argue that customer perceptions affect the quality of online banking services. Their research shows that if the website of online banking has reasonable and convenient navigation and search tools and a high degree of interaction, then users will have a positive perception of the interface friendliness and service quality of the website of online banking. Minocha and Dawson believe that commercial Banks can maintain current users and attract more potential customers by creating a real, safe and reliable atmosphere when users use online banking to conduct business. Joseph. Metal. Studied the influence of ATM, mobile phone and Internet on the delivery of service quality of commercial Banks by designing a measurement scale [1]. Jun and Cai studied the elements that constitute the service quality of online banking by collecting customer messages through BBS and BBS on the website of Gomez Advisors.[2]The results show that the service quality of online bank is influenced by customer service, product service and network system. Brode rick and Vachira pornpuk found that the prompt information set in the service operation of commercial Banks, the key events occurred in the service transaction process and the customer 
participation and participation ability had the most rapid impact on the service evaluation. [3]

For Internet banking service quality of domestic related research has formed a certain result, Rafnar and Wang Wukui think: online banking services, care and safety reliability of three dimensions will directly affect the user perceived satisfaction when using online banking, and the users of Internet banking service quality evaluation of a significant impact [4]. Wang chun believes that online banking is a new form of organization and operation of commercial Banks. It takes a long time for Banks and users to understand and be familiar with their business procedures and to understand and master relevant skills [5]. Liang Qingqing believes that to improve the quality of online banking services, efforts should be made to establish a highquality service platform, improve good consultation and personalized services, and improve the safety of online banking services.[6]Store Yu Jia he stand was thought: the financial service provided by the bank on the net is mostly on the network flow and transfer of funds, it can increase the customer perception of security risk, so the user evaluation of Internet banking service quality evaluation standard is different from the traditional service quality evaluation standard, Internet banking service quality is mainly composed of reliability, safety, efficiency and timeliness of the four factors of dealing with problems[7]. According to the research of Shuai Jiaying and Liu Chunjiang, there are four main factors that directly affect the customer perception of the service quality of enterprise online banking, which are the overall quality, network system quality, product quality and bank-enterprise relationship. [8]

\section{B. The Establishment of Theoretical Model}

In this study, SERVQUAL model was used to evaluate the service quality of online banking. SERVQUAL theory is a new service Quality evaluation system based on Total Quality Management (TQM) theory in service industry. SERVQUAL divides service quality into five levels: Tangibles, Reliability, Responsiveness, Assurance and Empathy. Based on the current consideration of network security, I have added the level of security, security. Each level is subdivided into several questions, and users are asked to rate the actual feelings of each question through questionnaires. It is illustrated by the 23 specific factors that it establishes.

\section{SELECTION AND DESIGN OF QUESTIONNAIRE INDICATORS}

The design of this questionnaire was based on SERVQUAL five models and combined with the actual situation of considering network security at present, so I added the level of security (security refers to the density of online banking on user information and the security ability of user login process). Index design is divided into six dimensions: responsiveness, tangibility, reliability, assurance, empathy and security. The questionnaire consists of two parts. The first part is about the understanding of some basic questions of the respondents, such as education background, income, etc., in order to have a preliminary understanding of the sample structure of the questionnaire. The second part is the investigators according to accept service experience and feeling to fill in the corresponding problem, a total of 23 item, survey scale using likert five hierarchical evaluation method, score design for 1 to 5,1 don't agree with, 5 agreed, in between other score evaluation, each one possible answers are covered in this five options. The higher the score is, the greater the degree of satisfaction will be.

The corresponding specific indicators of each dimension are shown in "Table I":

TABLE I. DIMENSIONS AND INDICATORS

\begin{tabular}{|c|c|c|}
\hline Dimension & Code & Questions \\
\hline \multirow{4}{*}{ Tangibility } & A1 & The interface of the online bank is beautifully designed and visually attractive \\
\hline & A2 & The online banking service product description can be well illustrated \\
\hline & A3 & The entity bank that this net bank relies on has very good brand image \\
\hline & A4 & Brick-and-mortar Banks have high-quality service personnel and attractive hardware facilities \\
\hline \multirow{4}{*}{ Reliability } & B1 & The content of the service provided by the online bank is consistent with the promise in the advertisement \\
\hline & B2 & The online bank provides services at the same time as promised \\
\hline & B3 & The online bank provides accurate services according to customer requirements \\
\hline & B4 & The online banking system works well \\
\hline \multirow{2}{*}{ Responsiveness } & $\mathrm{C} 1$ & Online banking has the ability to provide round-the-clock services \\
\hline & $\mathrm{C} 2$ & Customer complaints channels open and timely handling of customer problems \\
\hline \multirow{3}{*}{ Assurance } & D1 & Customer service staff have professional knowledge and ability \\
\hline & D2 & The website provides a lot of detailed help information \\
\hline & D3 & The information provided by the website is accurate and easy to understand \\
\hline \multirow{5}{*}{ Empathy } & E1 & This bank on the net can whole big hou handles each business for the user \\
\hline & E2 & The online bank attaches great importance to the special needs of customers \\
\hline & E3 & The online bank can provide personalized products and services \\
\hline & E4 & The online bank can be very active to understand the needs of customers \\
\hline & E5 & The online bank can timely notify users of personal events \\
\hline \multirow{5}{*}{ Security } & F1 & Online banking can ensure the security of the transaction process \\
\hline & $\mathrm{F} 2$ & I think using online banking can guarantee the security of personal information \\
\hline & F3 & I feel the service system is very stable when I use online banking \\
\hline & F4 & Using online banking can ensure the security of account information \\
\hline & F5 & Online banking regularly provides you with tools to enhance the security of your online banking system \\
\hline
\end{tabular}


consistent the results in the questionnaire, and an alpha factor between 0.80 and 0.90 is very good. The results showed that the Cronbach's alpha coefficient of the questionnaire as a whole was 0.943 , indicating that the reliability of the questionnaire was very good.

2) Validity test: Validity refers to the degree to which the measured results reflect the desired content of the investigation. The more consistent the measured results are with the content to be investigated, the higher the validity will be; otherwise, the lower the validity will be. Validity test refers to the analysis of the validity of the measurement results of the questionnaire, the test of the degree to which the measurement results of the designed questionnaire reflect the objective reality that it should reflect.

a) Factor fitness analysis test: SPSS was used to conduct KMO sampling suitability test and Bartlett spherification test for the valid sample data of this study. KMO is a sampling appropriateness indicator. The closer $\mathrm{KMO}$ is to 1 , the more common factors among variables, the more suitable the data are for factor analysis. The test results showed in "Table II", There are common factors among the correlation matrices representing evaluation indexes, not the identity matrix. Therefore, the data are suitable for factor analysis.

TABLE II. KMO AND BARTLETT TESTS

\begin{tabular}{|l|l|l|}
\hline \multicolumn{2}{|l|}{ KMO } & 879. \\
\hline $\begin{array}{l}\text { Bartlett's } \\
\text { sphericity } \\
\text { test }\end{array}$ & $\begin{array}{l}\text { Approximate } \\
\text { chi-square }\end{array}$ & 1561.432 \\
\cline { 2 - 3 } & Sf & 276 \\
\cline { 2 - 3 } & Sig. & 000. \\
\hline
\end{tabular}

b) Factor analysis: Principal component analysis was used for factor analysis. Because each item has a certain correlation among, so using oblique axis of Promax, oblique rotation factor load can be more easy to explain, factor analysis of variance contribution rate as shown in "Table III", from the table we can see in the top several of the variance contribution rate of the cumulated variance contribution ratio of the several principal components reached $59.598 \%$, consider it a few principal components to fully reflect the index contained in the message. In order to facilitate the identification and naming of common factors, the maximum variance rotation axis method is used for orthogonal rotation. The advantage of this method is that all factors remain orthogonal, but the variance difference of all factors is maximized to facilitate the explanation of factors.

TABLE III. OVERALL VARIANCE CONTRIBUTION RATE

\begin{tabular}{|c|c|c|c|c|c|c|}
\hline \multirow[b]{2}{*}{ Ingredients } & \multicolumn{3}{|c|}{ Initial solution } & \multicolumn{3}{|c|}{ The rotated solution } \\
\hline & Total & Percentage of variance & $\begin{array}{c}\text { Cumulative percentage of } \\
\text { variance }\end{array}$ & Total & Percentage of variance & Cumulative percentage of variance \\
\hline 1 & 10.459 & 45.474 & 45.474 & 10.459 & 45.474 & 45.474 \\
\hline 2 & 1.707 & 7.422 & 52.896 & 1.707 & 7.422 & 52.896 \\
\hline 3 & 1.555 & 6.760 & 59.655 & 1.555 & 6.760 & 59.655 \\
\hline 4 & 1.224 & 5.321 & 64.977 & 1.224 & 5.321 & 64.977 \\
\hline 5 & 1.063 & 4.621 & 69.598 & 1.063 & 4.621 & 69.598 \\
\hline
\end{tabular}


TABLE IV. PRINCIPAL COMPONENT LOAD MATRIX AFTER ROTATION

\begin{tabular}{|c|c|c|c|c|c|}
\hline & \multicolumn{5}{|c|}{ Ingredients } \\
\hline & 1 & 2 & 3 & 4 & 5 \\
\hline The interface is beautifully designed and visually attractive & 332. & 220. & 396. & 733. & 464. \\
\hline Service product description can be well illustrated & 541. & 384. & 343. & 765. & 414. \\
\hline The entity bank that the bank on the net relies on has very good brand image & 396. & 359. & 454. & 704. & 224. \\
\hline Brick-and-mortar Banks have high-quality service personnel and attractive hardware facilities & 417. & 497. & 665. & 723. & 058. \\
\hline The content of the services provided is consistent with the promise of the publicity & 400. & 554. & 796. & 491. & 260. \\
\hline Service delivery time is consistent with the time commitment & 476. & 257. & 749. & 367. & 432. \\
\hline We will provide accurate service according to customers' requirements & 571. & 546 & 778. & 453. & 237. \\
\hline The online banking system works well & 450. & 213. & 750. & 304. & 570. \\
\hline Online banking has the ability to provide round-the-clock services. & 585. & 246. & 757. & 288. & 625. \\
\hline Customer complaint channels are open and customer problems are dealt with in a timely manner & 430. & 646. & 741. & 351. & 372. \\
\hline Customer service staff have professional knowledge and ability & 696. & 587. & 548. & 424. & 764. \\
\hline The website provides a lot of detailed help information & 659. & 468. & 555. & 366. & 765. \\
\hline The information provided by the website is accurate and easy to understand & 467. & 491. & 396. & 213. & 789. \\
\hline Be able to handle all the business for the user & 357. & 735. & 413. & 373. & 760. \\
\hline Attach great importance to the special needs of customers & 455. & 770. & 400. & 247. & 373. \\
\hline Be able to provide personalized products and services & 518. & 780 . & 273. & 418. & 268. \\
\hline Can be very active to understand the needs of customers & 502. & 755. & 422. & 460. & 406. \\
\hline Be able to timely inform users of personal events & 697. & 753. & 531. & 447. & 399. \\
\hline Can ensure the security of the transaction process. & 776. & 400. & 407. & 417. & 362. \\
\hline Use can guarantee the security of personal information & 771. & 531. & 474. & 431. & 303. \\
\hline The service system is stable when used & 733. & 287. & 610. & 281. & 577. \\
\hline Can ensure the security of account information & 798. & 483. & 456. & 450. & 270. \\
\hline Regularly provide you with tools to enhance the security of online banking system & 777. & 455. & 389. & 362. & 391. \\
\hline
\end{tabular}

As can be seen from table above, the rotated factor load matrix reflects the degree of correlation between the principal factor and the original variable. The bold part of the data is between each factor and the original variables is larger, the load is big, because the main factors related to the original variable degree have high low, can be in accordance with the principle of relevance of the original variables can be divided into five types: the five factors of contribution rate were $45.474 \%, 7.422 \%, 6.760 \%, 5.321 \%, 4.621 \%$, the cumulative contribution rate was $69.598 \%$.It is named $\mathrm{f} 1, \mathrm{f} 2$, f3, f4 and f5 respectively. According to the meaning of these five factors, it can be classified into five dimensions of service quality, namely security, empathy, reliable response, tangible and assurance. The rotating factor load matrix is shown in table.

According to the score on each index, we can use it to investigate the nature of each index and the mutual relationship between the indicators. The result output by SPSS is the factor information as shown in "Table V":

TABLE V. COMPONENT SCORE COEFFICIENT MAtRIX

\begin{tabular}{|c|c|c|c|c|c|}
\hline & \multicolumn{5}{|c|}{ Ingredients } \\
\hline & 1 & 2 & 3 & 4 & 5 \\
\hline You often use or are most impressed by online banking & -005 & 007. & 012. & -005. & 591. \\
\hline The interface is beautifully designed and visually attractive & -043. & -032. & 064. & 254. & -092. \\
\hline Service product description can be well illustrated & 060. & -007. & 030. & 221. & -196. \\
\hline The entity bank that the bank on the net relies on has very good brand image & 007. & -017. & 038. & 322. & -059. \\
\hline $\begin{array}{l}\text { Brick-and-mortar Banks have high-quality service personnel and attractive hardware } \\
\text { facilities }\end{array}$ & 002. & 026. & 037. & 319. & 256. \\
\hline The content of the services provided is consistent with the promise of the publicity & 038. & 082. & 065. & 143. & 073. \\
\hline Service delivery time is consistent with the time commitment & -018. & -043. & 210. & 069. & 135. \\
\hline We will provide accurate service according to customers' requirements & 031. & 054. & 061. & 114. & 288. \\
\hline The online banking system works well & -019. & -025. & 217. & 000. & 019. \\
\hline Online banking has the ability to provide round-the-clock services. & 019. & -037. & 241. & -039. & 050. \\
\hline $\begin{array}{l}\text { Customer complaint channels are open and customer problems are dealt with in a timely } \\
\text { manner }\end{array}$ & -027 & 153. & 063. & 019. & 026. \\
\hline Customer service staff have professional knowledge and ability & 086. & 064. & 028. & 050. & -111. \\
\hline The website provides a lot of detailed help information & 048. & 056. & 142. & -055. & -057. \\
\hline The information provided by the website is accurate and easy to understand & -043. & 111. & 158. & -044. & -293. \\
\hline Be able to handle all the business for the user & 086. & 107. & 186. & -033. & -270. \\
\hline Attach great importance to the special needs of customers & 018. & 270. & 007. & -071. & 043. \\
\hline Be able to provide personalized products and services & 040. & 247. & -102. & 022. & 017. \\
\hline Can be very active to understand the needs of customers & 012. & 233. & -016. & 031. & -023. \\
\hline Be able to timely inform users of personal events & 103. & 059. & 020. & 030. & 017. \\
\hline Can ensure the security of the transaction process. & 205. & -045 & 024. & 010. & 087. \\
\hline Use can guarantee the security of personal information & 218. & 015. & -051. & 007. & 012. \\
\hline The service system is stable when used & 169. & -061. & 135. & -094. & -080. \\
\hline Can ensure the security of account information & 245. & -015. & -069. & 022. & -009. \\
\hline Regularly provide you with tools to enhance the security of online banking system & 179. & 022. & -010. & -030. & -013. \\
\hline
\end{tabular}


[4] Guo feng, Wang wukui. Empirical study on service quality evaluation of personal online banking [J]. Financial observation.2009.(11):39-43

According to the factor score coefficient and the standardized value of the original variable, the score of each observation, i.e., each variable, can be calculated, and the observed values can be further analyzed to obtain the score of each factor as shown in "Table VI":

TABLE VI. SCORES OF EACH FACTOR

\begin{tabular}{|l|l|l|}
\hline $\begin{array}{c}\text { Main } \\
\text { factor }\end{array}$ & Score & $\begin{array}{c}\text { Comprehensive } \\
\text { ranking }\end{array}$ \\
\hline f1 & 17519.56 & 1 \\
\hline f2 & 10596.92 & 2 \\
\hline f3 & 6429.77 & 4 \\
\hline F4 & 9934.56 & 3 \\
\hline F5 & 6518.59 & 5 \\
\hline
\end{tabular}

From the score, it can be concluded that f1 security accounts for the most important score, which means that from the perspective of the new generation, the online banking service quality is most concerned about security issues. Secondly, empathy occupies the second place in $\mathrm{f} 2$ score, which indicates that whether online banking can propose some personalized packages and requirements for users is also crucial. Then, f4 represents the tangibility, which also shows that the image of physical Banks also plays a great role in affecting the service quality of online Banks. Finally, the impact of F3's reliable responsiveness and f5's assurance on the service quality of online banking is relatively small compared with the previous factors.

\section{CONCLUSION}

The purpose of this paper is to investigate the current situation of the service quality of online banking from the perspective of the new generation, to find out the shortcomings of online banking in the service quality and the factors that restrict the improvement of online banking service quality. Based on this, this study took online banking of bank of China as the research object, designed a customer satisfaction questionnaire of online banking of bank of China based on SERVOQUAL service quality analysis framework theory, and analyzed the service quality of online banking of bank of China. After the statistical description, the customer satisfaction level of the online banking service of bank of China in tangible, guaranteed, empathic, reliable and responsive and security five aspects is obtained, and the following research conclusion is obtained: the online banking construction of bank of China is effective, but the service quality still needs to be further improved. And put forward corresponding suggestion and construction measure.

\section{REFERENCES}

[1] Joseph, M, MeClure, c. and Joseph b. Service quality in the banking sectorahe impact of technology on Service delivery[J]. International Journal of Bank Marketing, 1999, 17(4): 13-21.

[2] Jun,M, and Cai, s. The Key Deteminants of Internet Banking Service Quality: A Content Analysis[J]. The International Journal of Bank Marketing, 2001, 19(7): 276-281.

[3] Broderick, A.J. and Vanchirapornpork, s. Services quality in Internet banking: the importance of customer role [J]. Marketing Intelligence\&Planning, 2002, 20(6): 327-335.
[5] Wang chun, on the quality of online banking services -- a case study of industrial and commercial bank of China, e-commerce,2017 (02) :148-149.

[6] Liang qingqing, from the perspective of personal factors that affect the use of online banking [J], theoretical discussion, 2012, (02):33-18.

[7] Chu yujia, jing li, determinants and improvement measures of online banking service quality in China [J], times economics \& trade, 2011, (23).

[8] Yuan jiaying. Study on service quality of enterprise online banking and establishment of evaluation system [D]. Dong hua university: donghua university, 2004. 